\title{
Adverse drug reactions to tocolytic treatment for preterm labour: prospective cohort study
}

Roel de Heus, registrar of obstetrics and gynaecology, ${ }^{1}$ Ben Willem Mol, professor of perinatology and
clinical epidemiology, ${ }^{2,},{ }^{3}$ Jan-Jaap H M Erwich, gynaecologist and perinatologist, ${ }^{4}$ Herman P van Geijn,
professor of obstetrics, ${ }^{5}$ Wilfried J Gyselaers, gynaecologist and perinatologist, ${ }^{9}$ Myriam Hanssens,
professor of obstetrics, ${ }^{10}$ Linda Härmark, pharmacologist, ${ }^{7}$ Caroline D van Holsbeke, gynaecologist and
perinatologist, ${ }^{9}$ Johannes J Duvekot, gynaecologist and perinatologist, ${ }^{6}$ Fred F A M Schobben, professor of
pharmacology, ${ }^{8}$ Hans Wolf, gynaecologist and perinatologist, ${ }^{3}$ Gerard H A Visser, professor of obstetrics ${ }^{1}$

\section{ABSTRACT}

Department of Perinatology and Gynaecology, University Medical Centre Utrecht, KJ.02.507.0/

PO Box 85090, Utrecht,

Netherlands

${ }^{2}$ Department of Perinatology and Gynaecology, Maxima Medical Centre, Veldhoven, Netherlands

${ }^{3}$ Department of Perinatology and Gynaecology, Academic Medical

Centre, University of Amsterdam, Netherlands

${ }^{4}$ Department of Perinatology and Gynaecology, University Medical Centre Groningen, Netherlands

${ }^{5}$ Department of Obstetrics and Gynaecology, Free University Medical Centre, University of Amsterdam

${ }^{6}$ Department of Perinatology and Gynaecology, Erasmus University Medical Centre, Rotterdam

${ }^{7}$ Pharmacovigilance Centre Lareb, Hertogenbosch, Netherlands

${ }^{8}$ Department of Clinical Pharmacy, University Medical Centre, Utrecht

${ }^{9}$ Department of Perinatology and Gynaecology, Hospital Oost-

Limburg, Genk, Belgium

${ }^{10}$ Department of Perinatology and Gynaecology, University Hospital of Leuven, Belgium

Correspondence to: $\mathrm{R}$ de Heus R.deHeus-2@umcutrecht.nl

Cite this as: BMJ 2009;338:b744 doi:10.1136/bmj.b744 situations.
Objective To evaluate the incidence of serious maternal complications after the use of various tocolytic drugs for the treatment of preterm labour in routine clinical

Design Prospective cohort study.

Setting 28 hospitals in the Netherlands and Belgium.

Participants 1920 consecutive women treated with

tocolytics for threatened preterm labour.

Main outcome measures Maternal adverse events (those suspected of being causally related to treatment were considered adverse drug reactions) leading to cessation of treatment.

Results An independent panel evaluated the recorded adverse events, without knowledge of the type of tocolytic used. Of the 1920 women treated with tocolytics, 1327 received a single course of treatment (69.1\%), 282 sequential courses (14.7\%), and 311 combined courses (16.2\%). Adverse drug reactions were categorised as serious or mild in 14 cases each. The overall incidence of serious adverse drug reaction was $0.7 \%$. Compared with atosiban, the relative risk of an adverse drug reaction for single treatment with a $\beta$ adrenoceptor agonist was 22.0 (95\% confidence interval 3.6 to 138.0 ) and for single treatment with a calcium antagonist was 12 (1.9 to 69). Multiple drug tocolysis led to five serious adverse drug reactions (1.6\%). Multiple gestation, preterm rupture of membranes, and comorbidity were not independent risk factors for adverse drug reactions.

Conclusions The use of $\beta$ adrenoceptor agonists or multiple tocolytics for preventing preterm birth is associated with a high incidence of serious adverse drug reactions. Indometacin and atosiban were the only drugs not associated with serious adverse drug reactions. A direct comparison of the effectiveness of nifedipine and atosiban in postponing preterm delivery is needed.

\section{INTRODUCTION}

Preterm labour is the most reported cause of perinatal morbidity and mortality in the Western world. ${ }^{12}$ Tocolytic drugs have not been shown to improve fetal outcome, but are used to postpone delivery for 48 hours to allow for maximal effect of parenteral steroids administered to the mother and to enable the mother to be transferred to a centre with a neonatal intensive care unit. ${ }^{3}$ In the absence of any clear evidence that one tocolytic is more efficacious than another, relative safety is the main reason for choosing one over the other. The drugs registered for tocolysis include the $\beta$ adrenoceptor agonist ritodrine hydrochloride (United States and Europe) and the oxytocin receptor antagonist atosiban (Europe). Cyclo-oxygenase inhibitors and calcium channel blockers are also used for inhibiting preterm labour, ${ }^{45}$ although they are not currently registered for this indication.

$\beta$ adrenoceptor agonists cause adverse effects in women more often than any other tocolytic drug. ${ }^{67}$ In a clinical trial setting the oxytocin receptor antagonist atosiban was associated with fewer adverse effects than $\beta$ adrenoceptor agonists (relative risk 0.04, 95\% confidence interval 0.02 to 0.11 ) with comparable effectiveness (proportion of women with birth delayed for 48 hours; relative risk $1.1,0.9$ to 1.2$) \cdot{ }^{7-9}$ When compared with placebo, however, atosiban was not associated with a reduction in the incidence of neonatal respiratory distress syndrome, a serious complication of prematurity. ${ }^{9}$ Small studies using cyclo-oxygenase inhibitors have suggested that indometacin reduces the proportion of women delivering preterm compared with placebo (relative risk $0.2,0.1$ to 0.6 ) ${ }^{5}$ but its use has been limited because of concerns about adverse effects of cyclo-oxygenase inhibitors on fetal kidneys and ductus arteriosus and the increased risk of intraventricular haemorrhage and necrotising enterocolitis. ${ }^{1011}$ Calcium channel blockers seem to be more effective in postponing preterm delivery (relative risk $0.8,0.6$ to 0.9 ) and reducing neonatal respiratory distress $(0.6,0.4$ to 0.9$)$ than do $\beta$ adrenoceptor agonists. ${ }^{42}$ However, placebo controlled trials assessing calcium channel blockers are not available and recent reports have raised concerns about women's safety with use of these tocolytic drugs. ${ }^{13} 14$ The choice of first line tocolytic drugs for the 
treatment of preterm labour is therefore controversial because of inconclusive information on the relative safety of the various agents. ${ }^{1516}$ For example, most randomised trials on the efficiency and side effects of tocolytic drugs have generally been restricted to well defined (low risk) populations, excluding women with multiple gestation, preterm rupture of membranes, vaginal bleeding, diabetes, or a history of cardiovascular diseases. No prospective study has compared the adverse reactions of women to different tocolytic drugs in a routine clinical setting. We carried out a prospective cohort study in the Netherlands and Belgium to evaluate the incidence of serious maternal complications with the use of the various tocolytic drugs to treat preterm labour in routine clinical situations.

\section{METHODS}

We carried out an open label, prospective, cohort study. The cohort comprised consecutive women who were treated with tocolytic drugs according to local protocol for preterm labour in 28 hospitals in the Netherlands and Belgium during January 2006 to July 2007. We excluded women who were treated with tocolytic drugs for other reasons, such as external cephalic version for breech presentation or intrauterine resuscitation in case of suspected fetal distress during term labour. Potential participants were identified by the attending doctor or a study nurse and registered through a study website, which was accessible to participating clinics using centre specific access codes. We recorded the personal and obstetrical characteristics for each woman, including the date of birth, gestational age, parity, cervical dilation, blood loss, intact versus ruptured membranes, number of fetuses, and the presence of comorbidities such as cardiopulmonary disease, pre-eclampsia, hypertension, diabetes, placenta abnormalities, or polyhydramnios. We also recorded the type of tocolytic treatment and any maternal adverse event that required cessation of treatment. The attending obstetrician decided when to stop treatment in case of an adverse event. We carried out quality control of patient registration by checking the dispensing lists for tocolytics from the pharmaceutical department at each participating hospital. In all cases of possible adverse events the principal investigator completed a standard case report. If necessary, we retrieved additional data from the patients' files.

\section{Data assessment}

At the end of the registration period all adverse events were evaluated and classified by a panel of five members; three obstetricians (J-JHME, HW, MH) and two pharmacologists (LH, FFAMS). Four members of the panel worked in university hospitals and the fifth was an administrator at the Dutch Pharmacovigilance Centre.

The panel was initially asked to establish whether the registered adverse events satisfied the criteria of occurring during tocolysis and requiring discontinuation of tocolytic treatment in the opinion of the attending obstetrician, and then to classify the adverse events in terms of severity (serious or mild). The members individually reviewed all cases of adverse events, blind to the type of tocolytic used. For serious adverse events, we used the definition of the Council for International Organizations of Medical Sciences as a guideline. ${ }^{17}$ According to the council a serious adverse event is one that results in death, is life threatening, requires admission to hospital or prolongation of existing hospital stay, results in persistent or important disability or incapacity, or is a congenital anomaly or birth defect. On the basis of this definition, a serious adverse event in the context of tocolytic drugs was any of the following: severe hypotension (systolic blood pressure $<100 \mathrm{~mm} \mathrm{Hg}$ and $>20 \%$ drop compared with baseline values), severe dyspnoea, lung oedema, myocardial infarction, anaphylactic shock, admittance to intensive care, or maternal death. A mild adverse event was defined as an adverse event that led to cessation of tocolytic therapy (for example, tachycardia, nausea, dizziness, headache) but did not meet the criteria for a serious adverse event.

Each panel member subsequently received the list of adverse events, previously categorised as mild or serious, and the tocolytic used. They were asked to assess whether the adverse events were causally related to each tocolytic, using the causality categories of the World Health Organization: certain, probable, possible, unlikely, conditional, and non-assessable. ${ }^{18}$ Important criteria for the assessment of causality were the association in time between administration of the tocolytic and event, pharmacological features, medical plausibility, and exclusion of other causes. In cases of rechallenge with the tocolytic and recurrence of the adverse event, the causal relation to treatment was classified as certain. In case of a reasonable relation with time, not likely to be attributable to other drugs or disease, and a reasonable clinical response to withdrawal, the causal relation to treatment was classified as probable. If the adverse event could also be explained by concomitant diseases or use of other drugs, the causal relation to treatment was classified as possible. For adverse events with an improbable time relation or a plausible explanation provided by concomitant diseases or the use of other drugs the causal relation to treatment was classified as unlikely. The cases with discrepant assessments were discussed during a plenary meeting and a consensus was reached in all cases. We defined all adverse events that were considered as possibly, probably, or certainly related to tocolytic treatment as adverse drug reactions.

\section{Analysis}

We classified the administration of tocolytics according to three courses of treatment: single (one tocolytic), sequential (multiple tocolytics given separately in sequence), or combined (multiple tocolytics given simultaneously). The primary outcome of the study was the incidence of serious adverse drug reactions to tocolytics. In each of the three treatment categories we calculated the incidence of a tocolytic related adverse 
Table 1 | Obstetrical characteristics of women who received tocolytic treatment. Values are numbers (percentages) of women

\begin{tabular}{|c|c|c|c|c|c|c|}
\hline \multirow[b]{2}{*}{ Variables } & \multicolumn{4}{|c|}{ Single course treatment } & \multirow[b]{2}{*}{$\begin{array}{c}\text { Sequential } \\
\text { courses }(n=282)\end{array}$} & \multirow[b]{2}{*}{$\begin{array}{l}\text { Combined courses } \\
\qquad(n=311)\end{array}$} \\
\hline & $\begin{array}{c}\text { Atosiban } \\
(n=575)\end{array}$ & $\begin{array}{l}\text { Nifedipine } \\
(n=542)\end{array}$ & $\begin{array}{c}\beta \text { mimetics } \\
(n=175)\end{array}$ & $\begin{array}{l}\text { Cyclo-oxygenase inhibitors } \\
\qquad(\mathrm{n}=35)\end{array}$ & & \\
\hline Singleton pregnancy & $441(77)$ & $441(82)$ & $159(81)$ & $28(80)$ & $213(76)$ & $224(72)$ \\
\hline Parity 0 & $294(51)$ & $284(52)$ & $92(53)$ & $10(29)$ & $151(54)$ & $182(59)$ \\
\hline Preterm rupture of membranes & $162(28)$ & $162(30)$ & $35(20)$ & $3(9)$ & $59(21)$ & $87(28)$ \\
\hline Cardiac history & $15(2.6)$ & $10(1.8)$ & $3(1.7)$ & 0 & $3(1)$ & $4(1.3)$ \\
\hline Diabetes types 1 and 2 and gestational & $5(0.9)$ & $4(0.7)$ & 0 & 0 & $3(1)$ & $2(0.6)$ \\
\hline
\end{tabular}

drug reaction. For single course treatments, we carried out a separate analysis for each type of tocolytic. We then calculated the relative risk, the associated 95\% confidence interval, and the number needed to harm, using the single course tocolytic with the lowest incidence as a reference category. Using logistic regression we carried out a subgroup analysis of possible contributing factors to the incidence of tocolytic related adverse drug reactions, such as multiple gestation, medical history, or any obstetric comorbidity.

\section{RESULTS}

From January 2006 to July 2007, 1920 women were treated with tocolytic drugs in 28 hospitals in the Netherlands and Belgium. The mean maternal age was 29.8 years (interquartile range 26.4-33.3 years), and the mean gestational age was 29 weeks (interquartile range 27-31 weeks). Table 1 summarises the obstetrical characteristics of these women and the types of tocolytic treatment they received. The tocolytic agents used, either singly, combined, or sequentially, were the calcium channel blocker nifedipine ( $\mathrm{n}=1022,34.3 \%)$ the oxytocin antagonist atosiban $(\mathrm{n}=1248,41.9 \%)$, the $\beta$ adrenoceptor agonists ritodrine and fenoterol $(\mathrm{n}=411$, $13.8 \%$ ), the cyclo-oxygenase inhibitor indometacin

Table 2 | Serious maternal adverse events associated with tocolytic treatment

\begin{tabular}{|c|c|c|c|c|}
\hline Serious adverse event & Tocolytic & $\begin{array}{c}\text { No of } \\
\text { fetuses }\end{array}$ & $\begin{array}{c}\text { Intensive } \\
\text { care }\end{array}$ & Causality \\
\hline Dyspnoea & Ritodrine & 1 & No & Probable \\
\hline Dyspnoea & Fenoterol & 1 & No & Probable \\
\hline Dyspnoea & Atosiban, nifedipine, and ritodrine* & 1 & No & Probable \\
\hline Dyspnoea & Fenoterol & 1 & No & Probable \\
\hline Dyspnoea & Nifedipine & 2 & No & Possible \\
\hline Dyspnoea & Atosiban and fenoterol* & 1 & Yes & Possible \\
\hline Hypotension & Nifedipine & 1 & No & Probable \\
\hline Hypotension & Nifedipine & 1 & No & Certain \\
\hline Hypotension & Nifedipine & 2 & No & Certain \\
\hline Hypotension & Nifedipine & 1 & No & Certain \\
\hline Cardiac failure & Atosiban then fenoterol $\dagger$ & 1 & Yes & Possible \\
\hline Hypoxia & Nifedipine and ritodrine* & 2 & No & Probable \\
\hline Lung oedema & Atosiban, nifedipine, and fenoterol* & 2 & Yes & Possible \\
\hline Lung oedema & Atosiban and nifedipine* & 1 & Yes & Probable \\
\hline Dyspnoea & Fenoterol & 1 & No & Unlikely \\
\hline Deep vein thrombosis & Ritodrine then nifedipine $\dagger$ & 2 & No & Unlikely \\
\hline
\end{tabular}

*Combined courses: event occurred after simultaneous administration of all indicated tocolytics.

${ }^{\dagger}$ Sequential courses: event occurred after administration of second tocolytic.
( $\mathrm{n}=261,8 \%)$, magnesium sulphate $(\mathrm{n}=18,0.6 \%)$, and transdermal nitroglycerin, a nitric oxide donor $(\mathrm{n}=4)$.

Adverse events were recorded in 38 women in 17 hospitals. The panel rejected seven cases: in four cases the tocolytic had not stopped preterm labour and was therefore discontinued, in one case the dose of the tocolytic was reduced but treatment was not stopped, in one case treatment was stopped because of fetal tachycardia and not to a maternal event, and in one case treatment was stopped because of the inappropriate use of a $\beta$ mimetic in a woman with diabetes. Of the remaining 31 cases, 16 were categorised as serious adverse events and 15 as mild (tables 2 and 3). A causal relation to treatment was considered as unlikely in two cases of serious adverse events (table 2) and in one case of mild adverse events (table 3). These cases were therefore not included in further analyses, leaving 14 serious adverse drug reactions and 14 mild adverse drug reactions. Four women needed intensive care, all after multiple treatment with tocolytics. All the women who experienced adverse events recovered without persistent or major disability or incapacity. No fetal deaths were reported during treatment and none of the mild or serious adverse drug reactions was followed by fetal or neonatal death.

Among 575 women treated with a single course of atosiban, none had a serious adverse drug reaction and one had a mild adverse drug reaction (0.2\%; table 4$)$. Among 542 women treated with nifedipine, five had a serious adverse drug reaction $(0.9 \%)$ and six had a mild adverse drug reaction (1.1\%). Among 175 women treated with $\beta$ adrenoceptor agonists, three had a serious adverse drug reaction (1.7\%) and four had a mild adverse drug reaction $(2.3 \%)$. The number needed to treat to prevent a serious adverse drug reaction with atosiban compared with $\beta$ adrenoceptor agonists was 59 (lower limit of 95\% confidence interval was 35) and compared with nifedipine was 108 (lower limit of 95\% confidence interval was 56). In comparison with atosiban, the relative risk of an adverse drug reaction (mild and serious combined) with $\beta$ adrenoceptor agonists was 22.0 (95\% confidence interval 3.6 to 138.0) and with nifedipine was 12 (1.9 to 69.0).

Ten different combinations of atosiban, $\beta$ adrenoceptor agonists, nifedipine, and cyclo-oxygenase inhibitors were recorded in 311 instances. In patients who received these combinations, five serious $(1.6 \%)$ and one mild $(0.3 \%)$ adverse drug reactions were observed. No serious adverse drug reaction was reported in 
Table 3 Mild maternal adverse events associated with tocolytic treatment

\begin{tabular}{|c|c|c|c|}
\hline Mild adverse events & Tocolytic & No of fetuses & Causality \\
\hline Hypotension & Nifedipine & 2 & Possible \\
\hline Hypotension & Nifedipine & 1 & Probable \\
\hline Hypotension & Nifedipine & 1 & Probable \\
\hline Tachycardia & Nifedipine & 1 & Possible \\
\hline Tachycardia & Atosiban then nifedipine* & 1 & Possible \\
\hline Tachycardia & Ritodrine & 1 & Probable \\
\hline Tachycardia & Fenoterol & 1 & Probable \\
\hline Tachycardia & Nifedipine & 1 & Probable \\
\hline Tachycardia & Fenoterol & 1 & Certain \\
\hline Nausea & Atosiban & 1 & Possible \\
\hline Headache & Atosiban then nifedipine* & 1 & Possible \\
\hline Headache & Fenoterol & 1 & Probable \\
\hline Headache & Atosiban, nifedipine, ritodrine, and minitran $\dagger$ & 1 & Probable \\
\hline Headache & Nifedipine & 1 & Probable \\
\hline Syncope & Nifedipine & 1 & Unlikely \\
\hline
\end{tabular}

*Sequential courses: event occurred after administration of second tocolytic.

†Combined courses: event occurred after simultaneous administration of all indicated tocolytics.

combinations using cyclo-oxygenase inhibitors $(\mathrm{n}=143)$. In 282 women who received sequential courses one serious and two mild $(0.7 \%)$ adverse drug reactions were observed, all during administration of the second drug; once with a $\beta$ mimetic drug and twice with nifedipine.

The use of tocolytics was recorded in 414 women with a multiple pregnancy. Four of these women had a serious tocolytic related adverse drug reaction compared with women with a singleton pregnancy (relative risk $1.5,95 \%$ confidence interval 0.39 to 5.0 ). Two of the women $(2.0 \%)$ were treated with a single course of nifedipine $(\mathrm{n}=101)$ and two $(2.4 \%)$ were treated with combined courses $(n=84)$. Logistic regression showed that preterm rupture of membranes, blood loss, and other obstetric comorbidities were not independently related to an adverse event.

\section{DISCUSSION}

The use of $\beta$ adrenoceptor agonists or multiple tocolytics to prevent preterm labour is associated with a high incidence of serious adverse drug reactions. Indometacin and atosiban were the only tocolytic drugs not associated with serious adverse reactions.

Randomised studies on the efficiency of tocolytics and adverse events associated with these drugs have generally been restricted to well defined (low risk) populations, excluding women with multiple pregnancies, preterm rupture of membranes, vaginal bleeding, diabetes, or a history of cardiovascular diseases; however, many of the case reports on adverse drug reactions to tocolytics have been associated with these conditions. ${ }^{13}$ 19-22 We assessed the occurrence of serious maternal adverse drug reactions related to the use of different tocolytics in a routine clinical setting. Our results therefore apply to situations normally encountered in clinical practice, where both low risk and high risk cases are observed. Intense monitoring in a trial setting is, however, likely to reveal all mild and serious maternal side effects, whereas under-reporting of adverse experiences cannot be excluded in prospective multicentre cohort studies where the intensity of monitoring - especially of blood pressure - may vary between hospitals.

In our study the overall incidence of serious tocolytic related adverse drug reactions was low (0.7\%). The incidence of serious adverse drug reactions in women receiving combined courses of tocolytics (16.2\% of all patients) was, however, high (1.6-2.5\%). As there is no evidence that treatment with combined tocolytics is superior to single or sequential treatment, we believe that combined treatment should be discouraged. In women treated with a single tocolytic, the incidence of serious adverse drug reactions was $1.7 \%$ for $\beta$ mimetic agents and $0.9 \%$ for nifedipine. No serious adverse drug reaction was observed after treatment with a single course of atosiban. Most of the adverse drug reactions reported in women treated with nifedipine were related to the effects of the drug on blood pressure. In six of the seven cases, hypotension developed within two to four hours after the start of tocolysis. The treatment schedule was usually the following: two to four doses of $10 \mathrm{mg}$ sublingual nifedipine every 15 minutes, followed by $20 \mathrm{mg}$ slow release nifedipine every four hours. With such a regimen, plasma levels are likely to peak between 60 and 80 minutes after administration and cause a concomitant fall in blood pressure. ${ }^{23}$ In our series, the relevance of this finding seems low, given the absence of obvious fetal compromise in the 542 women treated with nifedipine only. Fetal compromise after a hypotensive episode has been found in studies of animals and in several cases in humans, including one fetal death. ${ }^{24-26}$ In the case of the death of the fetus, blood pressure dropped after the

Table 4 | Adverse drug reactions associated with single tocolytic treatment. Values are numbers (percentages) of women unless stated otherwise

\begin{tabular}{|c|c|c|c|c|c|}
\hline \multirow[b]{2}{*}{ Tocolytic } & \multirow[b]{2}{*}{ No of patients } & \multicolumn{2}{|c|}{ Severity of adverse drug reaction } & \multirow[b]{2}{*}{ Total } & \multirow[b]{2}{*}{ Relative risk* $(95 \% \mathrm{Cl}$} \\
\hline & & Serious & Mild & & \\
\hline$\beta$ mimetics & 175 & $3(1.7)$ & $4(2.3)$ & $7(4.0)$ & 3.8 (1.6 to 9.2$)$ \\
\hline Nifedipine & 542 & $5(0.9)$ & $6(1.1)$ & $11(2.0)$ & $2.0(0.8$ to 4.8$)$ \\
\hline Atosiban & 575 & 0 & $1(0.2)$ & $1(0.2)$ & 0.07 (0.01 to 0.4$)$ \\
\hline Cyclo-oxygenase inhibitors & 35 & 0 & 0 & 0 & NA \\
\hline
\end{tabular}




\section{WHAT IS ALREADY KNOWN ON THIS TOPIC}

Preterm birth is the major cause of perinatal mortality and mobidity

Tocolytics are used to postpone delivery to allow for maximal effect of steroids given to the mother and transfer of the mother to a centre with a neonatal intensive care unit

The choice of first line tocolytic drug is controversial because of inconclusive information on the mother's safety with use of various tocolytic agents

\section{WHAT THIS STUDY ADDS}

$\beta$ adrenoceptor agonists or multiple tocolytics for preventing preterm birth are associated with a high incidence of adverse drug reactions

Indometacin and atosiban are the only tocolytic drugs not associated with serious adverse drug reactions in women

A direct comparison of effectiveness between nifedipine and atosiban in postponing preterm delivery is needed agonists as a common comparator, has been published. ${ }^{29}$ The analysis showed no significant differences in effectiveness in delaying delivery, but a significant reduction in neonatal respiratory distress syndrome with nifedipine. Whether this reduction is attributable to a difference in effectiveness of the drug or to differences between the analysed trials in terms of lack of blinding or concealment or of corticosteroid administration remains uncertain.

An ideal tocolytic should postpone delivery at low costs without maternal and fetal side effects. None of the tocolytics described in this study fulfils these criteria. We found that combined treatment or a single treatment using $\beta$ adrenoceptor agonists led to a higher incidence of serious adverse drug reactions, and such treatments should be discouraged. The overall incidence of serious adverse drug reactions with a single course of nifedipine in a singleton pregnancy seems to be low, but not absent. Atosiban has the best maternal and fetal safety profile but at considerable cost. A direct comparison of effectiveness between oxytocin antagonists and calcium channel blockers is lacking. Moreover, larger studies with different dose regimens for nifedipine are necessary to compare efficiency and maternal side effects.

The participating hospitals were: Academic Medical Centre Amsterdam, Hans Wolf; Lucas Andreas Hospital Amsterdam, Celine M Radder; Free University Medical Centre Amsterdam, Herman P van Geijn, Annemiek C Bolte; Sint Augustinus Hospital, Antwerpen, Tina BVBA Vanderheijden; University Hospital Antwerpen, Yves Jacquemyn; Gelre Hospital Apeldoorn, Anjoke JM Huisjes; General Hospital Klina Brasschaat, Patricia Crijns; Maas and Kempen Hospital, Dirk Lauwagie; Sint Jan Hospital, Brugge, Anne Loccufier; Bronovo Hospital, the Hague, Casper AG Holleboom; University Hospital Gent, Walter Parewijck, Marleen Temmerman; Hospital Oost-Limburg Genk, Wilfried J Gyselaers, Caroline van Holsbeke; University Medical Centre Groningen, Jan-Jaap HM Erwich; Atrium Medical Centre Heerlen, Frans JME Roumen; Sint Fransiscus Hospital, Jan Schreurs; University Hospital Leuven, Myriam Hanssens; Maria Hospital Noord-Limburg Neerpelt, Bart Bollen; Sint Antonius Hospital Nieuwegein, Erik van Beek; Canisius-Wilhelmina Hospital Nijmegen, Jan MJ Sporken; Erasmus Medical Centre, Rotterdam, Hans J Duvekot; Laurentius Hospital Roermond, Chantal BM Wingen; Saint Trudo Hospital, Sint Truiden, Christa Eerdekens; Twee Steden Hospital, Tilburg, Addy P Drogtrop; Sint Jozef Hospital Turnhout, Jan Aerts, Myrrith

Hulsbergen; University Medical Centre Utrecht, Margo Graatsma, Gerard HA Visser; Maxima Medical Centre Veldhoven, Ben-Willem Mol; and Isala Hospital Zwolle, Jim van Eijck.

Contributors: All authors had full access to the data (including statistical reports and tables) in the study and take responsibility for the integrity of the data and the accuracy of the data analysis.

Funding: This research was funded by an unconditional grant from Ferring Pharmaceuticals BV, Hoofddorp, The Netherlands.

Competing interests: WJG did a retrospective cohort study on tocolysis in 2006 (not published) which was supported by an unconditional grant from Ferring Pharmaceuticals.

Ethical approval: This study was approved by the medical review ethics committee of University Medical Centre Utrecht. interval 0.3 to 0.9 ), closure of the ductur arteriosus among 403 women closure of the ductus arteriosus among 403 women treated short term (up to 48 hours). ${ }^{5}$ Nonetheless, on the basis of the volume of evidence the authors concluded that firm conclusions on the efficiency and safety for neonates when using cyclo-oxygenase inhibitors to prevent preterm delivery could not be drawn.

Large randomised controlled trials comparing atosiban with nifedipine are lacking. An indirect comparison of atosiban with nifedipine, using $\beta$ adrenoceptor
1 Ananth CV, Vintzileos AM. Epidemiology of preterm birth and its clinical subtypes. J Matern Fetal Neonatal Med 2006;19:773-82.

2 Hoyert DL, Mathews TJ, Menacker F, Strobino DM, Guyer B. Annual summary of vital statistics: 2004. Pediatrics 2006;117:168-83.

3 Crowley P. Prophylactic corticosteroids for preterm birth. Cochrane Database Syst Rev 2000(2):CD000065.

4 King JF, Flenady VJ, Papatsonis DN, Dekker GA, Carbonne B. Calcium channel blockers for inhibiting preterm labour. Cochrane Database Syst Rev 2003(1):CD002255.

5 King J, Flenady V, Cole S, Thornton S. Cyclo-oxygenase (COX) inhibitors for treating preterm labour. Cochrane Database Syst Rev 2005(2):CD001992. 
6 Anotayanonth S, Subhedar NV, Garner P, Neilson JP, Harigopal S. Betamimetics for inhibiting preterm labour. Cochrane Database Syst Rev 2004(4):CD004352.

7 The Worldwide Atosiban versus Beta-agonists Study Group. Effectiveness and safety of the oxytocin antagonist atosiban versus beta-adrenergic agonists in the treatment of preterm labour. The Worldwide Atosiban versus Beta-agonists Study Group. Br J Obstet Gynaecol 2001;108:133-42.

8 French/Australian Atosiban Investigators Group. Treatment of preterm labour with the oxytocin antagonist atosiban: a double-blind, randomized, controlled comparison with salbutamol. Eur J Obstet Gynecol Reprod Biol 2001;98:177-85.

9 Coomarasamy A, Knox EM, Gee H, Khan KS. Oxytocin antagonists for tocolysis in preterm labour-a systematic review. Med Sci Monit 2002;8:RA268-73.

10 Major CA, Lewis DF, Harding JA, Porto MA, Garite TJ. Tocolysis with indomethacin increases the incidence of necrotizing enterocolitis in the low-birth-weight neonate. Am J Obstet Gynecol 1994;170(1 Pt 1):102-6.

11 Norton ME, Merrill J, Cooper BA, Kuller JA, Clyman RI. Neonatal complications after the administration of indomethacin for preterm labour. N Engl J Med 1993;329:1602-7.

12 Papatsonis DN, Van Geijn HP, Ader HJ, Lange FM, Bleker OP, Dekker GA. Nifedipine and ritodrine in the management of preterm labour: a randomized multicenter trial. Obstet Gynecol 1997;90:230-4

13 Van Geijn HP, Lenglet JE, Bolte AC. Nifedipine trials: effectiveness and safety aspects. Br J Obstet Gynaecol 2005;112(suppl 1):79-83.

14 Oei SG. Calcium channel blockers for tocolysis: a review of their role and safety following reports of serious adverse events. Eur J Obstet Gynecol Reprod Biol 2006;126:137-45.

15 Simhan HN, Caritis SN. Prevention of preterm delivery. N Engl J Med 2007;357:477-87.

16 Rosen LJ, Zucker D, Oppenheimer-Gazit V, Yagel S. The great tocolytic debate: some pitfalls in the study of safety. Am J Obstet Gynecol 2001;184:1-7.

17 Venulet J, Bankowski Z. Harmonising adverse drug reaction terminology: the role of the Council for International Organizations of Medical Sciences. Drug Saf 1998;19:165-72.
18 Meyboom RH, Hekster YA, Egberts AC, Gribnau FW, Edwards IR. Causal or casual? The role of causality assessment in pharmacovigilance. Drug Saf 1997;17:374-89.

19 Oei SG, Oei SK, Brolmann HA. Myocardial infarction during nifedipine therapy for preterm labour. N Engl J Med 1999;340:154.

20 Verhaert D, Van Acker R. Acute myocardial infarction during pregnancy. Acta Cardiol 2004;59:331-9.

21 Nassar AH, Ghazeeri G, Usta IM. Nifedipine-associated pulmonary complications in pregnancy. Int J Gynaecol Obstet 2007;97:148-9.

22 Abbas OM, Nassar AH, Kanj NA, Usta IM. Acute pulmonary oedema during tocolytic therapy with nifedipine. Am J Obstet Gynecol 2006;195:e3-4.

23 Papatsonis DN, Bos JM, van Geijn HP, Lok CA, Dekker GA. Nifedipine pharmacokinetics and plasma levels in the management of preterm labour. Am J Ther 2007;14:346-50.

24 Van Veen AJ, Pelinck MJ, van Pampus MG, Erwich JJ. Severe hypotension and fetal death due to tocolysis with nifedipine. $\mathrm{Br} J$ Obstet Gynaecol 2005;112:509-10.

25 Harake B, Gilbert RD, Ashwal S, Power GG. Nifedipine: effects on fetal and maternal hemodynamics in pregnant sheep. Am J Obstet Gynecol 1987;157(4 Pt 1):1003-8.

26 Blea CW, Barnard JM, Magness RR, Phernetton TM, Hendricks SK. Effect of nifedipine on fetal and maternal hemodynamics and blood gases in the pregnant ewe. Am J Obstet Gynecol 1997;176:922-30.

27 Vaast P, Dubreucq-Fossaert S, Houfflin-Debarge V, Provost-Helou N, Ducloy-Bouthors AS, Puech F, et al. Acute pulmonary oedema during nicardipine therapy for premature labour; report of five cases. Eur J Obstet Gynecol Reprod Biol 2004;113:98-9.

28 Hodges R, Barkehall-Thomas A, Tippett C. Maternal hypoxia associated with nifedipine for threatened preterm labour. Br J Obstet Gynaecol 2004;111:380-1.

29 Coomarasamy A, Knox EM, Gee H, Song F, Khan KS. Effectiveness of nifedipine versus atosiban for tocolysis in preterm labour: a metaanalysis with an indirect comparison of randomised trials. BrJ Obstet Gynaecol 2003;110:1045-9.

Accepted: 2 December 2008 